\title{
On the Construction of the Probability Theory and Mathematical Statistics Course under Transformation Trend of Local Universities
}

\author{
Chen Yanfeng ${ }^{1, a}$ \\ ${ }^{1}$ College of Mathematics, Tonghua Normal University Jilin Province, China \\ awenjianke2007@163.com
}

\begin{abstract}
Keywords: Probability theory and mathematical statistics course; Course construction; Local universities transformation; Talent training; Curriculum system
\end{abstract}

\begin{abstract}
We should stick to the demand for traction the principle of probability theory and mathematical statistics course, keep the course of sustainable development, adhere to the quality as the core principles, and ensure the coordinated development of curriculum construction. There are many problems in the construction of curriculum system for the probability theory and mathematical statistics course, such as, the practical features need to strengthen, the structure of curriculum content should be expanded, the teaching quality of teachers need to strengthen, the teaching methods need to reform and other issues. Aiming at the above problems, put forward the reform of the following measures: around the goal of innovation training on talents, strengthen the practical characteristics of course system; facing the transformation of new challenges, broaden the structure content of the curriculum system in universities; facing the transformation of new challenges, improved the teachers' ability and quality cultivation; facing the transformation of new challenges, improved method in the course teaching mode. And these measures will be applied to the actual teaching, must pay much effort to the probability theory and mathematical statistics course construction, make contribution to promote transformation and development pattern of innovation talent training.
\end{abstract}

\section{Introduction}

The probability theory and mathematical statistics course is mathematics research on the statistical regularity of random phenomena. It is widely used in natural science, social science, engineering technology, military, industrial and agricultural production. With the popularization of computer, it is a data analysis and decision making theory and method of information processing. Teaching the course of can not only enable students to obtain the knowledge of probability theory and mathematical statistics, and lay a good foundation for the study of follow-up courses; it can also cultivate and train the students to have a strong abstract thinking and random thinking ability, rigorous logical reasoning ability, as well as the basic theory and method of using stochastic mathematical analysis and massive data processing from screening, extract the important information; more importantly, it can make students from many of the things the "perceptual" into "the fundamental law" of things, so as to cultivate the students' inquiry ability for anything, exploring the truth of scientific spirit and independent thinking and solving practical problems. Therefore, the probability theory and mathematical statistics course is not only an important public basic course of all school majors, but also supporting curriculum in mathematics, applied mathematics and statistics professional. It is of great significance to strengthen the construction and development of probability theory and mathematical statistics course for mathematics major and related majors in local universities.

\section{Principles in the Construction of Probability Theory and Mathematical Statistics Course}

The implementation of higher education strategy and promote local universities to promote school career transition is a good opportunity for the sustained and healthy development, according to the overall arrangement of Education Ministry "on local universities restructuring and development guidance" and the specific requirements of basic school based on the application of type discipline of 
the Provincial Department education transformation and development, for local economic and social development actually, in order to cultivate practical talents as the main target of the reform in all areas. So it is of course construction, in the construction work of probability theory and mathematical statistics course, should adhere to the principle of the following aspects[1].

Adhere to the Principle of Demand for Take Care, Raction, Keep the Course of Sustainable Development. The probability theory and mathematical statistics course of Mathematics College was first opened in 1978. Has achieved fruitful results, decades development history shows that, in order to ensure the sustainable development of curriculum construction, we must adhere to the demand of the local economic and social development for talent as the principle of traction.

Original specialized training based on teacher education personnel tasks, and increase the practice should be the task of training talents, the talent culture presents new challenges, the previous teaching concepts, curriculum system, teaching content has not fully adapted to the future talent training goal with the rapid development of information technology, the new requirements of the higher education reform deepening and the main service object is proposed, the local universities talent training mode has changed greatly[2]. The change of talent training mode in local universities put forward new and higher requirements for the course construction. On the one hand, we should follow the social demand for talent frontier, continue to provide qualified talents for local economic and social development; on the other hand, we have to work hard to finish the task of college education planning in transition. Therefore, we must continue to strengthen the curriculum construction, training of professional and technical personnel at the same time, to set up suitable for transformation of education curriculum system, teaching system and strive to finally establish and perfect system, multi-level and multi angle of probability theory and mathematical statistics. So, in order to maintain the sustainable development of curriculum construction, to avoid being out of embarrassment, but also to contribute to the cultivation of high-quality talents for the society and the development of local economy.

Adhere to the Principle of Quality as the Core, Ensure the Coordinated Development of Curriculum Construction. The coordinated development of the curriculum reform for probability theory and mathematical statistics should reflect the development of the scale, the quality and the benefit of the course and meet the needs of the local economic and social development. And from the point of view of scale, quality, structure and benefit and the development of the overall effect, the core of the curriculum reform is the quality, if the curriculum reform does not pay attention to the quality, then no amount of curriculum construction and perfect, level and rich, angle and broad, meaningless, cultivate really meet the needs of social development, master the basic skills of excellent application type talent. Therefore, the probability theory and mathematical statistics in the curriculum reform, we should adhere to the principle of quality as the core, ensure the coordinated development of the curriculum reform [3].

Problems in the Construction of Probability Theory and Mathematical Statistics Course. The probability theory and mathematical statistics course after decades of development for mathematics, professional training and lay a good foundation. Now, in the face of new challenges brought by the change of the social demand for talent, facing the transformation of school education, some problems emerged, which need to be solved.

Strengthen the Practical Characteristics of Curriculum System. On the one hand, with the continuous development of professional construction, the original professional connotation in the gradual expansion of professional courses and content involved has greatly increased, the probability and statistics course of the traditional advantages of decline; to study the effect of traditional content in training the professionals is limited; the traditional teaching mode and content cannot meet the practice of cultivating high-quality applied talents demand[4]. On the other hand, in the face of local colleges and universities in transition, the new curriculum system has not been fully established, these are watered down curriculum system of probability theory and mathematical statistics on the practical characteristics, affecting our better service for the local economic and social goals[5]. 
Widen the Structure Content of Curriculum System. Local economic and social development needs not only for the basic education of teachers, but also the need for industrial transformation and upgrading and the development of public services. And our current curriculum system is still in accordance with the requirements of the past society of talent. Even in the traditional areas, the traditional content of courses can not meet the demand. Because with the combination of the rapid development of society and modern education, computer programming technology has become an indispensable basic skills of college graduates of the elite. Therefore, on the one hand, we need to link the original experimental course in probability theory and mathematical statistics course increases, supporting the establishment of the experimental teaching system, combines the course of probability theory and mathematical statistics and mathematical modeling and mathematical software, mathematical experiment courses, and the ability to cultivate students' ability of computer programming; on the other hand and we need to establish a new curriculum system, teaching content, in order to meet the needs of the transformation and development of the school [6].

Strengthen the Teachers' Quality of Curriculum Teaching. Firstly, local universities are generally lack of professional teachers for probability theory and mathematical statistics, knowledge is not inherited the system and not comprehensive, so how to establish a high quality suitable for the local universities transformation training mode innovation and talent development course system blindly; secondly, the era of knowledge explosion, the existing knowledge of probability theory and mathematical statistics teachers master has been unable to meet the future needs of teaching, even some knowledge has facing the crisis of being eliminated. Therefore, we need to constantly update the knowledge structure, their knowledge need to constantly strengthen.

Reform the Teaching Methods of Curriculum Teaching. In recent years, although the probability theory and mathematical statistics course have some reform of teaching methods and curriculum system, for example, open experiment course, has established a test database, the related content in the related basic theory research achievements and understanding into the classroom, stimulate the learning enthusiasm of many students on the course of probability theory and mathematical statistics. But in the way of teaching did not change significantly, in the teaching process, it is still used a teacher and a textbook as the center of the organization, as well as the injection type of the main teaching methods, some monotonous, not conducive to mobilize the enthusiasm of the students. Therefore, the teaching methods of probability theory and mathematical statistics need to be changed to fully stimulate the initiative of all students [7].

\section{Countermeasures for Strengthening the Construction of the Probability Theory and Mathematical Statistics Course}

In order to realize the benign development of the probability theory and mathematical statistics course, we must to around local economic and social demand for talents, around the function and mission of local universities, aiming at the existing problems, take effective measures.

Around the Goal of Innovation Culture on Talents, Strengthen the Practical Features of Course System. It is a new target for the local college mathematics and applied mathematics to cultivate the practical applied talents of the social and local economic development. Talent demand changes in society requires our school to complete the talent training mode innovation under the conditions of software and hardware facilities is not complete, to continue to train a large number of specialized personnel and compound talents[8]. As the only local normal university in the southeastern part of Jilin Province, we have the dual mission of carrying teachers for local elementary education and transporting high level technical talents for local economic construction. Therefore, the theory of probability and mathematical statistics course construction must closely around the actual demand of society for talents, taking the opportunity of traction, strengthen the original course construction in the basis of professional curriculum reform, taking into account can be used for the transformation of education curriculum construction, according to the transformation development requirements of the relevant documents, update and supplement necessary teaching content, establish new suitable for transformation of education curriculum system, and combined with the actual needs, 
identify the course contents, aiming at the frontier of, accelerate the pace of the construction of curriculum, for innovative talents training mode of service[9].

Face the New Challenges in Transition, Broaden the Content Structure of Curriculum System. On the one hand, deepen study, pay attention to the cross and integration of probability theory and mathematical statistics of professional disciplines and other professional fields, to innovation of the frontier problem of professional disciplines and research results enrich the teaching content, to promote a high level of teaching to a high level of scientific research and teaching in a high level of education of high-quality personnel, high-quality talent to promote social development, forming a virtuous circle between the achievements in scientific research, teaching content, talent training and the effective transformation. On the other hand, to strengthen the exchange and communication of the employer and the, fully understand transformation of education for curriculum construction requirements, solid and strong complement weak, increasing new teaching content, establish perfect experimental course system, attention and other curriculum system between the mutual promotion and balanced development, and the resulting architecture of multi angle, multi-level, system, perfect teaching system [10].

Face the New Challenges in Transition, Improve the Teachers' Ability and Quality Cultivation. High school teacher, highly for fan. The horizons of teachers determines the students knowledge range. Teachers should not only teach students the knowledge in the classroom, but also to guide the students to establish a correct outlook on life, world outlook and values. In order to cultivate qualified to meet the needs of local economic and social development professionals, teachers must have rich knowledge and knowledge. Therefore, in the transformation of the challenge, teachers should recognize their own weaknesses, and to make up for their deficiencies. Strengthen contact with employer, as far as possible a comprehensive and in-depth understanding of the actual demand by employers, and thus constantly learning new knowledge, update their knowledge structure, improve their quality and self-cultivation, to adapt to the needs of transformation and development[11].

Face the New Challenges in Transition, Improve the Method and Mode in Course Teaching. In the teaching process, teachers play a leading role. Teachers should shoulder this responsibility, should be timely understanding of the latest developments in higher education, renew the ideas of education, deepen the teaching and research methods, change teaching methods. According to the probability theory and mathematical statistics course teaching practice in recent years, in view of the problems occurred in the process of teaching, the universities will continue to strengthen construction of probability theory and mathematical statistics course, probability theory and mathematical statistics course was named university level excellent course in 2006, is currently being submitted to the provincial excellent courses in the sprint, we are in accordance with the new construction target and plan launched a multi-faceted curriculum construction, such as improve the teaching material system, teaching, content enrichment, establishment of experimental course system and teaching mode of exploration, hoping to take this opportunity, pay more efforts to make probability theory and mathematical statistics course construction become provincial excellent courses, provincial-level quality courses [12].

The cultivation of innovative mode in local universities and the transformation trend of talents, the curriculum construction is one of the key points and determine the success of the transition of education, and teachers of local universities is mainly responsible for this important task, this is a solemn mission entrusted by history and the era of the local university teachers, in order to cope with the transformation of school development, meet new challenges, as the probability theory and mathematical statistics course teachers, combined with their own work, around local economic and social development of the talent demand, innovative talent training mode, compare with provincial outstanding courses, provincial excellent curriculum standards, make the curriculum construction of probability theory and mathematical statistics well, the contribution model innovation for the transformation and development of talents to promote school culture. 


\section{Acknowledgements}

This work was financially supported by the Education Department of Jilin Province Education Science "Twelfth Five Year Plan" Fund Project, No. GH14398 (On the construction of the probability theory and mathematical statistics course under transformation trend of local universities). "The innovative research on talents training mode based on the reform of mathematics curriculum reform (JY2015069) ", which was approved by Tonghua Normal University as "the higher education teaching reform research project".

\section{References}

[1] Y.F. Chen, The teaching reform of modern control theory course under applied talents cultivation mode, Journal of Tonghua Normal University (2014) 80-82.

[2] G.L. Wu, The application teaching reform in higher vocational education for probability theory and mathematical statistics, Guangxi Education (2011)37-39.

[3] W.Wang, Y.Q.Zhao, W.F. Liu, A few points exploration of probability theory and mathematical statistics in the teaching reform, University Education (2015)97-98.

[4] L.Q.Li, Li C.Qi, to improve classroom teaching quality of probability theory and mathematical statistics. Education Forum (2015)175-176.

[5] Y.Zhao, B.Wang "Probability theory and mathematical statistics" teaching content,

[6] Method, model and application ability cultivation of students study and practice. Journal of Jilin Institute of Chemical Technology (2015)74-77.

[7] S.M.Ross, Introduction to Probability Models, USA: ELSEVIER, 2010.

[8] S.S. Mao, Probability Theory and Mathematical Statistics. Beijing: Higher Education Press, 2011. 